\section{The Mental Life of Some Animals}

\author{
Mark Rowlands \\ The University of Alabama \\ Tuscaloosa
}

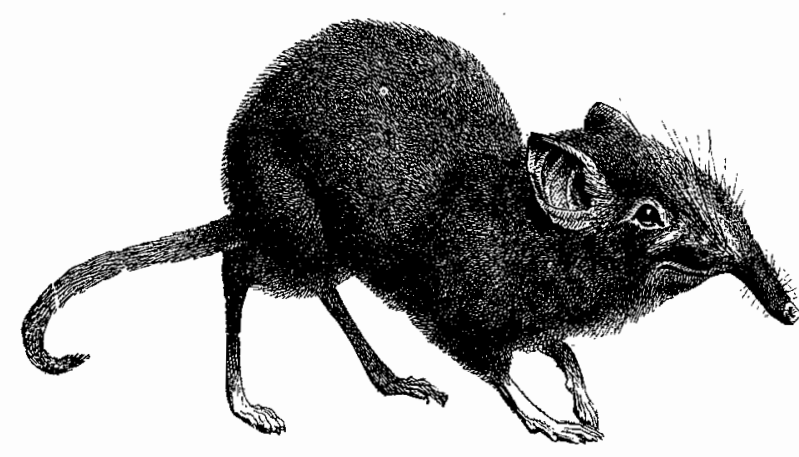

Introduction

The ascription of content based states-beliefs, desires, preferences, and so on-to nonhuman animals is still a subject of much debate in philosophy. Contemporary authors such as Donald Davidson, ${ }^{1}$ R.G. Frey, ${ }^{2}$ Norman Malcolm, ${ }^{3}$ and Stephen Stich ${ }^{4}$ have all argued that the ascription of beliefs, desires, and other content based mental states to nonhuman animals is in some way misconceived. One important sub-class of these arguments, largely associated with Stich but also present in the work of the others, is based on the claim that it is impossible to specify the content of such states as applied to nonhuman animals. The primary aim of this paper is to provide a sound theoretical underpinning to the practice of ascribing content, and, hence, content based states, to nonhuman animals. It will be argued that this practice is grounded in neither crude anthropomorphism, nor in sentimentalism, but in solid, down to earth, evolutionary biology.

Such a claim, of course, will, if correct, have significant consequences vis-a-vis the application of ethical theory to nonhuman animals. Most attempts to bring nonhumans into the moral sphere presuppose, at

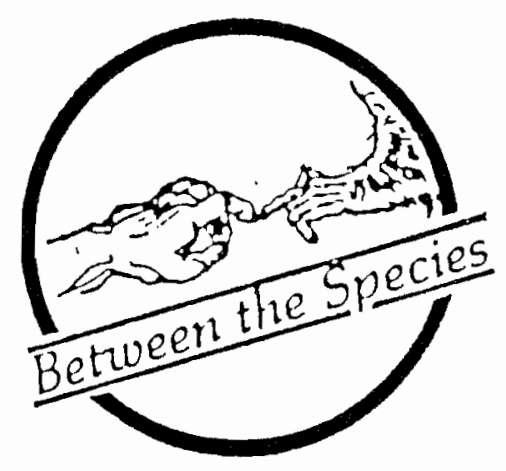

least implicitly, that they are possessors of contentful states. Many of the more plausible attempts are quite explicit about this. Thus, Peter Singer's argument for animal liberation derives from his preferenceutilitarianism, and its application to nonhumans presupposes that they can be the bearers of preferences. Since preferences are individuated by their content, this, in turn, presupposes that it is legitimate to ascribe content to nonhumans. Tom Regan's defense of animal rights depends on the claim that nonhumans can be subjectsof-a-life, where an individual is a subject-of-a-life only if it has beliefs, desires, perceptions, memories, etc. and a sense of the future, including their own future. All these are contentful states. Therefore, a sound defense of the practice of ascribing content to nonhuman animals can quite plausibly be regarded as a cornerstone of the attempt to bring them under the moral umbrella.

The opening sections discuss Stich's argument against the possibility of the ascription of content to nonhuman animals. It will be argued that the problems Stich discerns with such ascription stem not from the nature of such animals, but from the theory of meaning presupposed by Stich. This can be seen from the fact that, given the theory of meaning adopted by Stich, exactly the same problems can also be discerned in the ascription of content to human animals, even to those human animals who constitute normal members of our own cultural group. Attention will then be focused on a

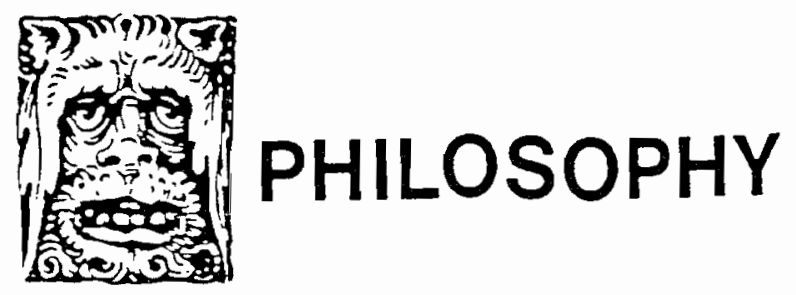


more adequate theory of meaning. The pivotal concept employed by this theory is that of reference, or representation, and the concept of reference will be explained in terms of the concept of biological function. The resulting theory, it will be argued, provides a sound theoretical framework for the ascription of content to both human and nonhuman animals.

\section{Stich on Ascription of Content to Nonhuman Animals}

Stephen Stich has argued that specifying the content of the beliefs of nonhuman animals is impossible. In "Do Animals Have Beliefs?," he argues that this entails that the whole issue is moot. The question has no answer. In his later book, From Folk Psychology to Cognitive Science, he takes a slightly more conciliatory stance when he claims that the question is hopelessly contextrelative. ${ }^{5}$ In some conversational contexts, ascription of content based states to a nonhuman animal would be correct, but in another context, ascription of the same content based state to the same animal at the same time would be incorrect. I shall begin this paper with a discussion of Stich's argument because I think he does provide the most carefui and most clearly thought out case against the possibility of ascribing content based states to nonhuman animals. The arguments I shall eventually marshal against $S$ tich can also be applied to the arguments of the other aforementioned authors.

In broad outline, Stich's argument can be represented as follows:

1. We can attribute content to a belief only if we assume that the subject of the belief has a broad network of related beliefs that is largely similar to our own.

2. Where a subject does not share a very substantial part of our own network of beliefs we are no longer capable of attributing content to that subject's beliefs.

3. Nonhuman animals do not share a substantial part of our own network of beliefs.

4. Therefore, we are incapable of attributing content to the beliefs of nonhuman animals.

5. But content is an essential element of belief. We can attribute beliefs to a subject only insofar as we can specify the content of those beliefs.

6. Therefore, we cannot attribute beliefs to nonhuman animals.
The same applies, mutatis mutandis, to all content based mental states.

Stich's argument is based on his analysis of the concept of belief, and the corresponding notion of belief content. According to Stich, the relation of contentidentity is, in fact, a similarity relation. The notion of the content of a belief can be factored into three elements: causal-pattern similarity, ideological similarity, and reference similarity.

A pair of belief states count as similar along the dimension of causal-pattern similarity if they have similar patterns of potential causal interaction with (actual or possible) stimuli. ${ }^{6}$ In addition to global causalpattern similarity, there are various dimensions along which a pair of belief states can be partially causalpattern similar. For example, a pair of belief states may interact similarly with other beliefs in inference but may have different links with stimuli. These beliefs would count as similar when the context focuses interest on inferential connections, but as rather dissimilar when the context focuses interest on the connections between belief and perception. Causal-pattern similarity is the feature which is focused upon by classical functionalist or conceptual role accounts of content.

The second sort of feature used to assess similarity of beliefs is what Stich calls ideological similarity. ${ }^{7}$ The ideological similarity of a pair of beliefs is a function of the extent to which the beliefs are embedded in similar networks of belief. Ideological similarity measures the 'doxastic neighbourhood' in which a given pair of belief states find themselves. As in the case of causal-pattern similarity, partial ideological similarity is often more important than global ideological similarity. Since belief states are compound entities, ideological similarity can be assessed separately for the several concepts that compose a belief. And context can determine which concepts are salient in the situation at hand. For example, suppose the context focuses on 'bourgeois.' Then, if Boris and Marie both say, 'Abstract art is bourgeois,' we may count them as having similar beliefs if their other beliefs invoking the bourgeois concept are similar, even though they have notably different beliefs invoking their abstractart concept. But if the difference in their conceptions of abstract art looms large in the context, our judgment will be reversed, and they will not count as having similar beliefs.

The third sort of feature used in assessing belief state similarity is reference similarity. ${ }^{8}$ According to 
Stich, a pair of beliefs count as reference similar if the terms the subjects use to express the beliefs are identical in reference. What actually fixes reference is not an easy matter to decide. One prime candidate is the causal history of the term, a causal chain stretching back through the user's concept, through the concept of the person from whom he acquired the term, and so on back to the person or stuff denoted. A second candidate, defended by Burge, is the use of the term in the speaker's linguistic community. ${ }^{9}$ Neither of these accounts is free from difficulties. Stich does not wish to adjudicate between these accounts. He does say, however, that in his view context is an important determinant of reference. ${ }^{10}$

According to Stich, therefore, the notion of sameness of content, hence, the notion of sameness of belief, is a complex concept which straddles all three features of causal-pattern, ideological, and reference similarity. Depending on the context of discussion, one or more of these factors can assume primary importance.

I think Stich has, in fact, done a rather good job in analyzing the notion of content identity, and his account may be correct, or close to correct. My disagreement with Stich, however, centres around his treatment of reference similarity. His claim that a pair of beliefs count as reference similar if the terms the subjects use to express the beliefs are identical is without justification, and automatically prejudices the issue against nonlanguage users, and against language users who do not employ 'terms' as Stich seems to think of them. I shall argue that the relation of reference does not only, or even primarily, attach to the terms of a language. Reference is a natural (specifically, a biological) phenomenon based on the need of an organism to adapt to its environment. As such, internal states which have evolved in order to adapt an organism to its environmental niche have a referential function. Moreover, behaviour which has evolved in order to adapt an organism to its environmental niche can have a referential function. The notion of reference primarily attaches to internal states and to behaviour. Derivatively it can be applied to the terms of a language. Indeed, its application here depends on the fact that the use of language is a form of behaviour different only in degree from more primitive modes of behaviour.

I shall proceed as follows. Firstly, I shall try to show why the relation of reference is such a crucial component of content. Secondly, I shall argue that it is Stich's claim that reference similarity cannot be applied to nonhunan animals which creates the feeling that ascription of content to nonluunan animals is problematic. This can easily be seen from the fact that if we prescind from applying the relation of reference similarity to human animals, exactly the same problems in ascribing content arise, and this applies whether the human animals in question are so called marginal cases, or whether they are normal members of our own cultural group. Thirdly, I want to sketch an account of the relation of reference which will provide a sound underpinning for the practice of ascribing content based states to both human and nonhuman animals. I shall argue that such an underpinning is to be foundin the notion of teleology and the related notion of biological function.

\section{The Concept of Content}

The inadequacy of any theory of meaning or content which is based purely around the notions of ideological similarity or causal pattern similarity can be demonstrated by way of the sort of Twin Earth example made famous by Hilary Putnam and by Tyler Burge. ${ }^{11}$ Here is Putnam's version of the Twin Earth case.

We are to conceive of a near duplicate of our planet Earth: call it 'Twin Earth.' Except for certain features about to be noted, Twin Earth duplicates Earth in every detail. The physical environments look, and largely are, identical. Moreover, many inhabitants of Earth have duplicate counterparts on Twin Earth. These counterparts are type-identical with their corresponding Earthlings in point of neurophysiological constitution. They also share with their Earth counterparts identical experiential and dispositional histories, where these are specified non-intentionally. The key difference between the two planets can be explained thus: the liquid on Twin Earth that runs in rivers and taps is qualitatively identical with the liquid that we, on Earth, refer to with the term 'water' ; it is indistinguishable from water by any casual test. Indeed, the Twin Earthlings refer to their liquid using the term 'water.' However, the substance they refer to using that term is not water. It is not the substance whose chemical structure consists of two parts of hydrogen to one part of oxygen. Rather, the liquid on Twin Earth has a radically different chemical structure $-X Y Z$. Therefore, water on Earth is not the same substance as what is denoted by the term 'water' on Twin Earth. Despite being qualitatively identical, 
water, and what goes by the same name on Twin Earth-call it the substance retaw-are distinct substances.

Suppose Herbert ${ }_{1}$ is an English speaker of Earth, and Herbert 2 is his Twin Earth counterpart. Neither knows the physical structure of the substance which he calls 'water.' We can make the following assumptions about the two Herberts. Firstly, we can suppose that they are identical in point of physical constitution. Secondly, we can suppose that they have the same inner functional states, the same behavioural dispositions, and that they exhibit the same bodily movements; where all of these are non-intentionally specified. Given a nonintentional specification, functional states, behavioural dispositions, and bodily movements supervene on physical constitution. Thus, the second assumption is a consequence of the first. Identity of functional states, behavioural dispositions, and bodily movements entails that the two Herberts are identical in point of what Stich calls causal pattern.

Since neither of the Herberts is aware of the physical structure of the substance he calls 'water,' the following state of affairs is a definite possibility. There is a set $S$ of statements composed of S1: 'water is wet'; S2: 'water is colourless'; S3 'water is drinkable,'... Sn, such that both Herbert ${ }_{1}$ and Herbert instantiate $S$. That is, both Herbert $_{1}$ and Herbert, believe all and only statements $\mathrm{S} 1, \mathrm{~S} 2, \ldots$, Sn about what they call 'water.' That is, Herbert $_{1}$ and Herbert ${ }_{2}$ are ideologically identical, or ideologically exactly similar.

Thus, the assumption that Herbert ${ }_{1}$ and Herbert share the same causal pattern and the assumption that they share the same ideological network can be built into Putnam's thought experiment. But, even if this is true, it does not follow that the two Herberts share the same beliefs about water. In fact, Herbert 2 cannot have any belief about water. As Putnam points out, the form of words, 'water is wet' means something different in the mouth of Herbert ${ }_{1}$ than it does in the mouth of Herberh. The former's utterances of 'water' refer to water. The latter's utterances of the same phonetic form refer to retaw. Hence, the utterances differ in meaning because they differ in reference. Furthermore, the differences in meaning affect oblique occurrences in 'that'-clauses which specify. the contents of mental states. Herbert ${ }_{1}$ believes that water is wet. But Herbert, cannot have this belief since he has never been in contact with water. Herbert ${ }_{2}$ can only believe that retaw is wet.
Therefore, even though Herbert ${ }_{1}$ and Herbert ${ }_{2}$ are identical in point of causal pattern and ideological doxastic network, nonetheless, their utterances still differ in meaning, and their beliefs still differ in content. The inevitable conclusion is that to try to base an account of meaning and content purely around the notions of causal pattern similarity and ideological similarity will result in a seriously inadequate account of meaning and content. Instead, we must recognize that reference is an essential constituent of meaning and content.

This claim is no longer controversial. But laboring this point does serve to bring out clearly the fact that Stich's claim that reference similarity is not applicable to nonhuman animals is a very serious claim indeed. For if the concept of reference similarity could not be correctly applied to nonhuman animals, then there would not be any valid notion of content which could be ascribed to such animals. So, the claim that reference similarity cannot be applied to nonhuman animals is really the pivotal claim around which the whole of Stich's argument turns. But Stich offers neither justification nor defense of this claim Rather, it has the status of an assumption. Eventually I shall argue that this assumption is false. Firstly, however, I want to show how it is this assumption which leads us to think that the ascription of content based states to nonhuman animals is problematic. My strategy will be as follows: I shall try to show that exactly the same considerations which undermine our confidence in the ascription of content to nonhuman animals can also he applied to human animals, if we assume, as Stich does in the case of nonhuman animals, that the concept of reference similarity is inapplicable. This will be sufficient to show that it is Stich's denial of the applicability of reference similarity to nonhuman animals which undermines our ability to ascribe content to them. In particular, there is nothing intrinsically problematic with such ascription.

\section{Ideological Dissimilarity and the Case Against Animals}

Although human and nonhuman animals do exhibit causal-pattern differences, attribution of content based mental states to nonhuman animals becomes especially problematic when we focus on the ideological differences between the two. I shall confine my attention to such ideological differences. Does Fido believe there is a bone buried in the yard? If we focus on the 
ideological differences that obtain between Fido and humans, it is difficult to see how he can. The ideological differences undermine the view that Fido possesses the concept of a bone. For example, does Fido know that bones form part of the skeleton of certain sorts of creature? Does he know the general anatomical functions of bones? Does he know the composition of bones? Is it possible to explain the difference between real and fake bones to Fido? Such questions could be multiplied indefinitely. They all point to the conclusion that the doxastic network in which Fido's concept of a bone is situated is vastly different from our own. Thus, it does not seem possible to attribute content based states of the form ... believes that $X$ is a bone' to Fido, because Fido does not have the same concept of a bone as we do. Attribution of such a content based state is predicated upon our concept of a bone, and this is a concept which is not shared by Fido.

Thus, if we focus on the component of ideological similarity, the attribution of content based states to nonhuman animals becomes problematic. Every indication suggests that nonhuman animals do not share an appropriately similar doxastic ideological network of beliefs. Therefore, they cannot share our concepts. Therefore, they cannot share our contents. Therefore, they cannot share our beliefs (desires etc.).

\section{Marginal Cases and Not So Marginal Cases}

Some authors have pointed out that if Stich's argument can he applied to nonhuman animals, then it can also be applied to at least some human animals. ${ }^{12}$ Mentally handicapped humans, for example, will probably possess an ideological framework radically different from our own. The same can be said of young children. Similarly, normal individuals in cultures which are radically different from our own will also probably exhibit important ideological differences. So, if ideological dissimilarities undermine attribution of content based states to nonhuman animals, they will probably also undermine attribution of content based states to some human animals.

This claim does not bother Stich. In fact he endorses it. ${ }^{13} \mathrm{He}$ sees it as an inherent shortcoming in the practice of attributing content based states. This is the basis of Stich's syntactic theory of the mind: the view that the explanations of cognitive psychology should not invoke the semantic content possessed by mental states, but, instead, focus only on their syntactic properties.
Attribution of content is to play no role in a mature cognitive science. According to Stich, it is only by prescinding from attributions of content, that cognitive psychology can hope to develop explanations which apply to children, to the mentally handicapped, and to members of radically different cultures.

However, I feel the same sort of argument can be pushed further to an extent that Stich might not wish to endorse. Consider again the concept of a bone. It seems to be Stich's view that every description which a normal person of our society associates with the term 'bone' enters into the determination of the concept of a bone. But this cannot be right. It would render communication impossible. For it seems overwhelmingly likely that each distinct person will associate a slightly different set of information with the term. If this is so, and if every piece of information is relevant to the determination of the concept of a bone, then each distinct person will have a distinct concept of a bone. The idea that there is the concept of a bone, shared even by normal members of a single society, will have to be rejected. Similar remarks will apply, mutatis mutandis, to all, or almost all, terms of a given language. And the problem with this is that it makes any sort of communication impossible. It is not communication, but equivocation, which would be the rule, even between normal members of a single ideological group. In this way, the possibility of attribution of content based states to human animals, even to those human animals which form normal members of one's own society, would be undermined.

Two possible solutions to this problem suggest themselves, neither of which is very appealing. On the one hand, one might try to develop Stich's idea that the concept of content-identity is a similarity concept. This would provide us with a graded notion of content identity according to which you and I both more or less believe that there is a bone buried in the yard. There are three problems with this idea. First, it is not at all obvious that this move would solve the problem of communication. Secondly, the idea is, in any case, very dubious. The idea depends for whatever plausibility it has on confusing two quite different senses of 'more or less believing that $\mathrm{P}^{14} \mathrm{On}$ the one hand there is the relatively innocuous idea that agents can differ in their epistemic commitment to $\mathrm{P}$ (I will nail my flag to $\mathrm{P}$, you grant $P$ only your provisional assent). This idea is not at issue. On the other hand, there is the idea that propositional identity is a matter of degree. There is a 
big difference between the claim that one can more or less believe that $P$, and the claim that what one believes is more or less P. And it is the second claim that is at issue here. The idea that there might be something which is almost, but not quite, the proposition that a bone is buried in the yard seems to make little sense. Third, even if sense could be made of the graded notion of propositional identity, it would then be uncertain on what grounds Stich could then deny ascription of content to nonhuman animals. For it is certainly true that Fido does have some beliefs about bones. As Regan has argued, Fido can plausibly be viewed as having a preference-belief about bones. ${ }^{15}$ Fido, from time to time, desires a flavour that he finds in bones. And on the basis of his non-verbal behaviour-the fact that Fido would choose a bone over, say, a tree branch-we are justified in ascribing to Fido the belief that bones are related to his desires or preferences in the following way: bones satisfy certain desires he has and are to be chosen to satisfy those desires. If we accept, as I think we must, that Fido does have this crude sort of preference-belief, and if we accept the graded notion of propositional or content identity advocated by Stich, then we have grounds for saying that Fido can believe more or less that a bone is buried in the yard..$^{16}$ Of course, what Fido believes is not the same as what I believe, but the same also applies to what is believed by other normal members of my own cultural group.

The second possible solution to the problem facing Stich involves denying that every piece of information associated by speakers with bones enters into determination of the concept of a bone. We might distinguish between what we can call the cognitive concept, and what we can call the semantic concept of a bone. Consider the term 'bone.' The cognitive concept associated with this term is essentially relative to individuals, and consists of the set of all the information which that particular individual associates with the term. Thus, the cognitive concept is not uniform; even between normal individuals of the same ideological group. There is no such thing as the cognitive concept of a bone. The semantic concept, on the other hand, is not relative to the individual. It consists of certain core information which any competent user of a language $\mathrm{L}$ will associate with the term 'bone.' ${ }^{17}$ If Stich's case from ideological dissimilarity is based on the notion of cognitive concept, then it will not only undermine attribution of content based states to nonhuman animals, but also to human animals, even human animals which are normal members of the same ideological group. If Stich's case is based on the notion of semantic concept, then it is more promising. For, in this case, it seems that Stich's argument does provide us with reason for thinking that attribution of content based states to nonhuman animals (and to children, the mentally handicapped, and members of other cultures) is problematic. It is implausible to suppose that dogs, for instance, associate the same core set of descriptions with bones as semantically competent humans do.

There are two problems with introducing the notion of a semantic concept at this juncture. The first is that there is no evidence whatever to suggest that there is any such thing as a semantic concept. That is, there is no evidence whatever to suggest that all competent speakers associate the same core information with a given term, indeed, most available evidence points the other way. The notion of a semantic concept is a transcendental posit: one which is introduced as a condition of any meaningful communication. Transcendental posits are all very well, but their credibility is diminished to the extent that another explanation of the phenomenon they seek to ground is available. I shall argue, later, that there is another explanation of the possibility of meaningful communication. This explanation centres around the notion of reference, and does not invoke the notion of shared core information

Secondly, even if we allow Stich the notion of a semantic concept, the grounds for denying ascription of content to nonhuman animals again collapse. For even if nonhuman animals associate different core information with bones than do human animals, it still follows that they do associate some core information with bones (an example would be the preference belief cited by Regan). And this means that there is a semantic concept possessed by dogs, a (presumably distinct) semantic concept possessed by cats, etc. That is, this sort of approach leads naturally to the introduction of a species-specific notion of a semantic concept: The semantic concept of object X possessed by species $S$ is the core information which normal members of $S$ associate with $X$. And this leaves us with the interesting empirical task of finding out exactly what information normal members of $S$ do associate with $X$. In short, the argument only shows that the content we can attribute to nonhuman animals will be different from the content we can attribute to human animals. And all this means is that we have a genuine empirical task 
of finding out what content actually can be aftributed to nonhuman animals.

What I have tried to show in this section is that if Stich's argument can be used to undermine ascription of content to nonhuman animals, then it can also be used to undermine the ascription of content to all human animals, even those human animals who constitute normal members of our own cultural group. This claim, if correct, shows that the alleged problematic status of our ascriptions of content to nonhuman animals does not derive from the nature of the nonhuman animals themselves, but rather from the assumptions which underlie Stich's theory of meaning as it applies to nonhuman animals. Stich assumes that the relation of reference similarity is not applicable to nonhuman animals. The alleged problems with ascription of content to nonhuman animals stem directly from this assumption. In the remainder of this paper, I want to focus on the concept of reference, and show how a certain plausible theory of the reference relation provides a useful theoretical justification for our practice of ascribing content to nonhuman animals.

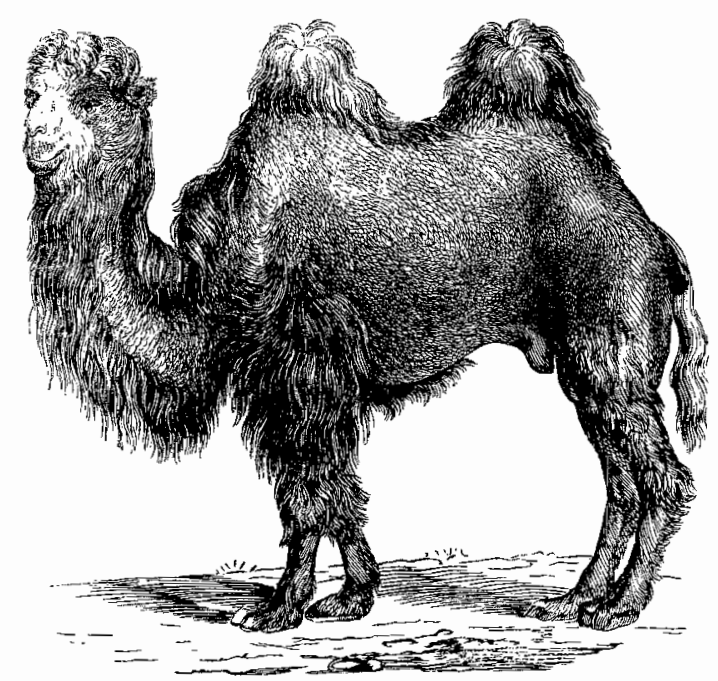

\section{How Nonhuman Animals Can Refer}

Stich thinks that the notion of content-identity is a similarity relation which can be factored into three components: causal-pattern similarity, ideological similarity, and reference similarity. But Stich thinks that the relation of reference similarity is inapplicable to nonhuman animals: "Since they have no language, reference similarity is out of the question." This follows from his characterization of reference similarity as a relation holding between the terms of a language and the world. However, Stich gives no justification or defense of this characterization. Stich does allow that some sort of derivative reference relation might obtain between animal concepts and the world. But he does not regard this as important enough to warrant the inclusion of reference similarity as a determinant of the content of animal belief states. In my view, this is to get the order of primacy reversed. Reference is a relation which holds primarily between internal states of creatures and the world, or between the behaviour of creatures and the world, and derivatively between terms or expressions and the world. The remainder of this paper will be concerned with defending this claim.

One of the principal projects of recent philosophy of mind has been providing an account of the relation of reference. This has been particularly important insofar as the notion of reference has been seen as the basis of the relation of intentionality. The intentionality of mental states, it is thought, derives from the referential relations holding between internal states and the world. The theory of reference I shall now present does have its opponents, but, in my opinion, is the best philosophical account currently available.

The theory I shall discuss is typically known as the teleological theory. ${ }^{18}$ Any teleological theory of representation or reference will employ, as a pivotal concept, what we can call relational proper function. ${ }^{19}$ The proper function of some organ or trait or process is what it is designed to do, what it is supposed to do, what it ought to do. Proper functions can come about either through the intentions of a designer, or through a mindless process like natural selection. A hammer has the proper function of knocking in nails in virtue of the intentions of its makers and users; a heart has the proper function of pumping blood in virtue of the selective pressures that have shaped the physiology of organisms. The notion of proper function is defined in terms of what an item should do, not what it actually does or is 
disposed to do. Thus, proper function cannot be defined causally or dispositionally: what something does, or is disposed to do, is not always what it is supposed to do. (The function of a sperm cell, for example, is to fertilize the female ovum. But the vast majority of sperm cells do not accomplish this task).

In the case of evolved organisms, function is always ultimately relative to survival (or gene reproduction): the function of an evolved characteristic is always ultimately to enhance reproductive capacity. Generally this means that it is to enable the organism to cope with its given environment: to locate food, evade predators, protect itself against heat or cold, and so on. An organism must be designed (by natural selection) according to the environmental constraints. And here is where the relationality of proper function arises. Proper functions are generally defined relatively to some environmental object or feature. Thus, the function of the chameleon's pigmentation mechanism is to make the chameleon the same colour as its immediate environment; the function of the lion's curved claws is to catch and hold onto large prey; the function of the bee's dance is to help other bees locate nectar, and so on. In each case we specify the function of the characteristic in terms of a relation to some environmental item. And the reason for this relational specification is that the very reason why the characteristics in question exist is that they have evolved to meet certain environmental pressures.

The core idea of the teleological theory of representation is that the mind and its contents are evolutionary products also. Thus, mental states will have their own distinctive relational proper functions. Therefore, on quite general evolutionary grounds, it is to be expected that such states as desires, beliefs, and perceptions will have environment directed functions. And identifying a given mental state via its semantic content is simply a way of identifying that state by way of its relational proper function. That is, the content of a mental states is (at least in part) determined by the relational proper function of that state. Content is a consequence of relational proper function. Thus, on this view, the externality of content, exhibited by the thought experiments of Putnam and Burge, is simply a reflection of the relationality of mental states; of the fact that any given mental state has evolved in order to fulfill a certain relational proper function.

Consider the desire for water, caused (we may safely suppose) by the organism's need for water. The relational proper function of this state is to bring about the introduction of water into the interior of the organism - to make it drink water. The desire exists in order to have certain environment directed effects (although, of course, it may not always have those effects). But, in specifying the environmental relatum of the relational proper function of the desire, we specify the object to which the desire refers, the environmental feature which the desire represents. In this way, the teleological theory understands the concept of reference in terms of the concept of relational proper function. Reference, is constituted by relational proper function.

Similar stories apply to cognitive mental states such as belief and perception. The relational proper function of the wolf's perception of the caribou is to indicate to the wolf the presence of the caribou. The reference and the content of the wolf's perception is a function of that perception's relational proper function. In this way, the wolf's need for food can be satisfied by acting appropriately. A basic biological duality operates here. On the one hand there is a need of the organism in respect of the world, on the other hand a sensor that indicates to the organism when the environment is the way it is needed to be. Desire and perception are mechanisms, installed by evolution, which perform these interlocking functions of sensitivity to need and sensitivity to what in the world will meet the need. Belief, on this view, is a mechanism superimposed on desire and perception, which functions so as to guide behaviour in the light of perception in order to satisfy desires. The teleological theory sees in these basic relational functions the deep roots of content.

The teleological theory does not purport to be a complete theory of content. If it did, it would attract the following obvious objection: traits and structures of organisms can have relational proper functions and yet not have propositional content. It does not seem appropriate, for example, to assign semantic content to hearts, despite their relational proper function. Rather, the teleological theory is advanced as a theory of reference. The teleological theory only purports to be a theory of a part of content: that part of content which is constituted by the relation of reference.

This being so, the teleological theory is best viewed within the framework of what has become known as the dual component theory of mental properties. ${ }^{20}$ This theory regards our intuitive conception of content as made up of two separable components. One component 
consists in an encoding or representation of things in the world. The other is made up of properly semantic relations such as reference which hold between such representations and the things represented. The former component, often called the internal component, is constitutive of the causal-explanatory role of belief, while the latter, often known as the external component, is bound up with our taking beliefs as things which refer to the world. We view beliefs both as states of the head explanatory of behaviour, and as items which enter into referential relations with the world. Content supervenes on both components taken together. Stich's account of content identity is tacitly a dual component theory. His notions of causal pattern similarity and ideological similarity belong to the internal component as characterized above, since they describe or advert to relations holding between beliefs, desires and other mental states. Reference similarity, on the other hand, is Stich's version of the external component, since it is based on relations which hold between mental states and the world. Both internal and external components are, according to the dual component theory, necessary for content.

The dual component theory faces the question of which component is more important in determining the content of a given mental state. The most attractive version of the theory, I believe, makes this a contextual matter; it varies from situation to situation depending largely on the interests we have in making the attribution of content. An important consequence of this is that it is possible to attribute a content based state to an organism purely upon the basis of knowledge of the external component, of the way the organism is referentially related to the world. In order to do this, one need not know anything about the internal component. That is, one need not know anything specific about the causal and ideological. network within which the attributed content is embedded. At most one need only know that there is such a network. On the other hand, it is also possible, depending on one's underlying interest, to attribute a content based state to an organism purely on the basis of knowledge of the various causal and ideological networks in which that content based state is embedded. One need not know any thing specific about the referential relations that the state bears to the world. At most, one need only know that there are such relations.

These considerations provide us with a useful framework for assessing the question of whether ascriptions of content based states to nonhuman animals are possible. In order to justify such ascriptions all we would need to show is:

1. The nonhuman animal to which the content based state is ascribed instantiates causal-pattern and ideological networks in which the ascribed content based state is embedded.

2. The ascribed content based state possesses a (known) relational proper function which relates it to some object, property, or relation in the environment of the nonhuman animal to which the content based state is ascribed.

(1) does not commit us to having any deep familiarity with either the causal or ideological networks. It claims only that the networks exist. (2) claims not merely that the content based state has a relational proper function, but also that one knows what it is. (1) and (2) provide a sufficient, but not a necessary, condition for attribution of the content based state in question. It seems pretty clear that condition (1) holds for both human and nonhuman animals. And given this is so, we can legitimately ascribe content based states to nonhuman animals purely on the basis of what we know about the referential relations which those states bear to the world.

In other words, it is possible, indeed justifiable, to ascribe a content based state purely on the basis of knowledge of the relational proper function of that state, provided one has good reason for thinking that the state is embedded in appropriate causal and ideological networks. That is, where causal pattern and/or ideological frameworks are unknown or uncertain, reference can carry the assignment of content. Thus, the claim that any content based states instantiated by nonhuman animals will probably be embedded in causal and ideological networks which radically differ from those possessed by human animals is irrelevant; it in no way undermines attribution of content based states to nonhuman animals.

To summarize, the positive framework I am advancing is based on the following claims: Firstly, reference is a partial determinant of the content of a belief, desire, perception etc. Secondly, the concept of reference can be spelled out in terms of the concept of relational proper function. Third, beliefs, desires, perceptions, and other content based states are hybrid entities, made up of two components, internal and 
external. The internal component is reflected in Stich's notions of causal pattern and ideological similarity. The external component is reflected in Stich's notion of reference similarity. Fourth, which component plays the primary role in the determination of content is a contextual matter. It varies from situation to situation depending on the interests we have in ascribing content. So, relative to interest $I_{1}$ it is possible to ascribe content $C$ purely on the basis of the internal component, providing one has reason to believe that an external component exists. And relative to interest $I_{2}$, it is possible to ascribe content $\mathrm{C}$ purely on the basis of the external component, providing one has reason to believe that an internal component exists. And, fifth, it is thus possible to ascribe a content based state to a nonhuman animal (or a human animal, for that matter) based purely on knowledge of the external component of that content. This amounts to the claim that it is possible to ascribe the state purely on the basis of the relational proper function of the state, providing one has reason to believe that the state is appropriately embedded in causal and ideological networks.

Therefore, the practice of ascribing content on the basis of relational proper function is legitimate. And this is what provides the framework and the justification for our practice of ascribing content to nonhuman animals. On this view, we are justified in attributing content to nonhuman animals because we have an underlying interest in describing the relations which obtain between organism and environment. These relations are incorporated into the notion of relational proper function and, hence, into the notion of reference. Thus, content can be ascribed purely on the basis of relational proper function. Viewed in this light, ascription of content based states to nonhuman animals is not crude anthropomorphism; neither is it sentimentalism; it is simply good old fashioned evolutionary biology.

\section{Notes}

${ }^{1}$ Donald Davidson, "Thought and Talk," in S. Guttenplan, ed., Mind and Language (Oxford, Oxford University Press, 1975), pp. 7-23. Also, "Rational Animals," in E. LePore and Brian McLaughlin eds., Acts and Events: Perspectives on the Philosophy of Donald Davidson (Oxford, Basil Blackwell, 1985).

${ }^{2}$ R. G. Frey, Interests and Rights: The Case Against Animals (Oxford, Oxford University Press, 1980), pp. 55ff.
${ }^{3}$ Norman Malcolm, "Thoughtless Brutes," in N. Malcolm, Thought and Knowledge (Ithaca, Cornell University Press, 1977), pp. $40-57$.

${ }^{4}$ Stephen Stich, "Do Animals Have Beliefs?," Australasian Joumal of Philosophy, Vol. 57 (1979), pp. 15-28. Stich's later, and more fully developed case against attributing beliefs to nonhuman animals is to be found in his From Folk Psychology to Cognitive Science: The Case Against Belief (Massachusetts, MIT Press, 1983), especially ch. 5.

${ }^{5}$ From Folk Psychology to Cognitive Science, op. cit., p. 106. My disagreement with Stich centres not around this claim which, in fact, I endorse. Rather, it lies with Stich's reasons for thinking that attribution of content based states to nonhuman animals is context-relative. Stich's case is largely based around the claim that his notion of reference similarity is inapplicable to nonhuman animals. I reject this claim entirely.

${ }^{6}$ Stich, From Folk Psychology to Cognitive Science, op. cit., p. 88-89.

${ }^{7}$ From Folk Psychology to Cognitive Science, op. cit., pp. 89.

${ }^{8}$ From Folk Psychology to Cognitive Science, op. cit., pp. $89-90$.

${ }^{9}$ See Tyler Burge, "Individualism and the Mental," Midwest Studies in Philosophy, vol. IV (1979), pp. 73-121. Also, "Individualism and Psychology," The Philosophical Review (1986).

${ }^{10}$ From Folk Psychology to Cognitive Science, op. cit., p. 90.

${ }^{11}$ See Tyler Burge, "Individualism and the Mental," op. cit., and "Individualism and Psychology," op. cit. Hilary Putnam, "The Meaning of 'Meaning,' "' in K. Gunderson ed., Language, Mind and Knowledge: Minnesota Studies in the Philosophy of Science vol. VII, (Minneapolis, University of Minnesota Press, 1975).

${ }^{12}$ See, for example, Richard Routley, "Alleged Problems in Attributing Beliefs, and Intentionality, to Animals," Inquiry, vol. 24, (1981), pp. 385-417.

${ }^{13}$ See From Folk Psychology to Cognitive Science, op. cit.

14 Jerry Fodor in his Psychosemantics (Massachusetts, MIT Press, 1987), pp. 57-58, discusses this issue and clearly distinguishes the two senses of 'more or less believing that p.' His comments on the strategy involving the graded notion of content identity: "This is the kind of yucky solution that they're crazy about in AI... Yuck."

${ }^{15}$ Tom Regan, The Case for Animal Rights, (University of California Press, 1983), pp. $57 \mathrm{ff}$. 
${ }^{16}$ This provides the basis of Regan's argument for ascribing beliefs to nonhuman animals. I cannot accept this argument since $I$ have rejected the graded notion of propositional identity adopted by Regan. In this paper I try to base such ascription on firmer grounds than I think are provided by this account of propositional identity.

${ }^{17}$ This issue constantly crops up in interpretations of Frege's notion of sense. This notion has been assimilated to what I have called a cognitive concept. Gareth Evans, however, in his excellent The Variefies of Reference has made a strong case for understanding the notion of sense in terms of what $I$ have called a semantic concept. I prefer Evans's interpretation.

18 The earliest statement of this view I know is Dennis Stampe, "Toward a Causal Theory of Linguistic Representation," Midwest Studies in Philosophy, vol. 2, (Minneapolis, University of Minnesota Press, 1977). See also, Fred Dretske, "Misrepresentation," in, Belief ed., Radu Bogdan, (Oxford, Oxford University Press, 1986), David Papineau, Reality and Representation (Oxford, Basil Blackwell, 1987). And, especially, Ruth Millikan, Language, Thought and Other Biological Categories (Massachusetts, MIT Press, 1984).

19 The expression 'relational proper function' is due to Millikan, ibid.

${ }^{20}$ See, Colin McGinn, "The Structure of Content," in A. Woodfield ed., Thought and Object (Oxford, Oxford University Press, 1982), Hartry Field, "Mental Representation," Erkenntnis 13, 1978, Ned Block, "Advertisement for a Semantics for Psychology," Midwest Studies in Philosophy, vol. X, (1986), Brian Loar, Mind and Meaning (Cambridge, Cambridge University Press, 1981).
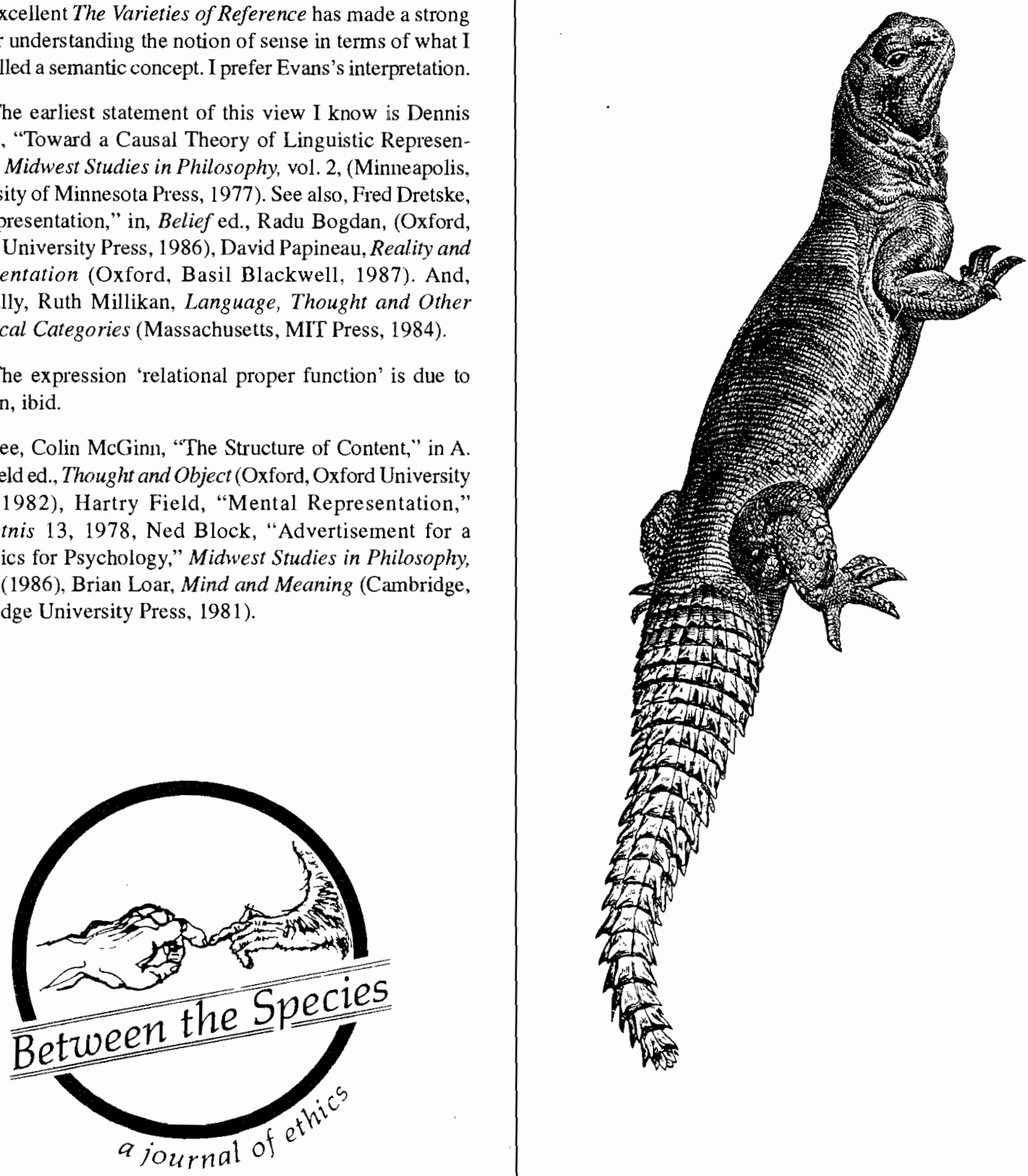